\title{
GOUT AN UNSOLVED PROBLEM
}

\section{BY J. BARNES BURT AND R. G. GORDON}

AT the recent International Conference on Rheumatic Diseases held at Bath a whole day was devoted to the subject of "Gout," but in spite of many interesting papers it must be confessed that no startlingly new contribution to our knowledge of this disease emerged from the discussion.

There is no reason to doubt that gout is essentially a disease of metabolism, but in spite of the recent major advances in biochemistry the only real progress that has been made in this direction is an improvement in the accuracy of tests which are supposedly useful in the diagnosis of the disease. Modern tests for uric acid in the blood are far superior to Garrod's thread test, but the increased accuracy of such tests is not so valuable as it might be, since it would appear that in the opinion of most authorities a low blood uric acid content is not inconsistent with a diagnosis of gout. A great deal of work has been carried out in estimating the sedimentation rate, leucocytosis, and the Cooke-Arneth's blood count in gout, but the observations proved to be of no help in diagnosis, for, in fact, most of such work emphasises points of resemblance between gout and rheumatoid arthritis rather than points of difference between it and other forms of arthritis. Considering the great advances in medicine in the twentieth century it is curious that our knowledge of a disease described by Hippocrates, Sydenham, and Garrod is still so chaotic, and a candid discussion on some peculiar features of gout ought to prove instructive.

\section{HeRedity}

Practically all authorities, with the exception of Freund (1938), agree that heredity is a very important factor. The following table shows the estimate of five experienced observers: 
HEREDITY IN GoUT

\begin{tabular}{|c|c|c|c|c|}
\hline \multicolumn{3}{|c|}{ Author. } & Per Cent. & Remarks. \\
\hline 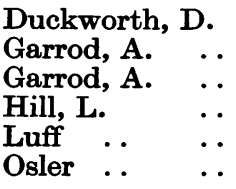 & $\begin{array}{l}\cdots \\
\cdots \\
\cdots \\
\cdots\end{array}$ & $\begin{array}{l}\ldots \\
\cdots \\
\cdots \\
\cdots\end{array}$ & $\begin{array}{c}50-75 \\
50 \\
75 \\
45 \\
81 \cdot 3 \\
50-60\end{array}$ & $\begin{array}{l}\text { Hospital patients. } \\
\text { Private patients. } \\
\text { Chiefly hospital patients. } \\
\text { Private cases only. }\end{array}$ \\
\hline
\end{tabular}

When one considers that gout may lie latent for a generation, and that parents may have died at an early age before gout showed itself, these figures are most impressive and almost justify Llewellyn's (1920) statement that an heredity factor is invariably present.

On the other hand, Freund (1938) considers that similarity of environment and similar habits and methods of living have led to the tradition that gout is hereditary. In the writers' opinion this is not a sound argument, for while our grandfathers may have been three- or four-bottle men, later generations are far more moderate in eating and drinking and probably take much more exercise to a later stage of life.

It is not uncommon to find a history of the so-called allergic diseases-eczema, asthma, hay fever and urticaria-in the relations of those suffering from true gout, which not only suggests an allergic factor in the production of gout, but also the presence of an hereditable diathesis such as is suggested especially by the French school.

As a matter of fact, it is difficult to find any record of exact work in recent literature. Hamilton (1900) says: "The conclusion I have arrived at is that the gouty habit of body has arisen as a variation, and as such is hereditarily transmissible, and that excess of diet and alcohol merely renders the habit of body apparent."

Thomson (1908) says: "All that can be said at present is that the predisposition to gout is an inborn character which, like any other, may be transmitted. Even if gout turns out to be definitely microbic, the general argument will not be seriously affected."

Baur, Fischer and Lenz (1931) say: "The inheritance of gout is as a rule a simple dominant. In many families the gouty 
diathesis can be traced through several generations, in other families the course of the heredity appears to be interrupted, this, perhaps, being because external influences (and especially the nature of the food) are of great importance as exciting causes of attacks of gout."

On the other hand, they remark that " gout may be included in the group of the idiosyncrasies or allergies. These are all characterised by a morbid susceptibility to substances which are harmless to normal individuals. Gout is an idiosyncrasy towards nucleoproteins of animal origin. There are many such morbid idiosyncrasies. B. N. Belaieff has described an hereditary idiosyncrasy towards egg albumin. We are indebted to Hanhart of Zurich for the sight of a number of interesting family trees compiled by him showing idiosyncrasies as the outcome of which allergic reactions could be induced by various substances in different members of the same family. The heredity appears to be dominant."

In gout, therefore, there would appear to be at least two hereditable factors, both of which require to be present, together with certain environmental influences, in order to determine the manifestations of the disease:

(1) A sensitiveness to certain articles of diet or certain products of metabolism.

(2) A tendency to store uric acid in the body, and to precipitate biurate crystals in certain tissues.

\section{Attacks produced by Specific Articles of Diet}

It is well recognised that in certain gouty people small quantities of such things as cider, asparagus, rhubarb and strawberries can produce typical attacks of gout, and that the same thing does not necessarily produce an attack in different people. This phenomenon is as definite and rapid as the production of urticaria by shellfish in susceptible persons; in fact, the phenomenon resembles in every respect a true allergic reaction. Where the "antigen" or equivalent sensitising substance-cider, for instance-is not recognised, and the cider continues to be taiken, a serious condition is set up in the affected joint and a traumatic element is introduced as a result of frequent use of an inflamed joint, which leads as a sequela to thickening of the synovial membrane, damage to the cartilage and changes in 
the bone. It is important to differentiate between the "attack" and the sequelæ of such an attack or attacks. Occasionally the reaction appears to be due to a summation of stimuli. One of us had a case who could take ham or beer separately with impunity, but if he had a lunch consisting of a plate of ham and a glass of beer he invariably got an attack of gout.

It is a possibility that lead may produce gout in the same way as cider, etc., but the curious geographical distribution of saturnine gout suggests that lead will not produce gout except in localities where gout is prevalent.

Saturnine Gout

\begin{tabular}{|c|c|c|c|}
\hline Author. & $\begin{array}{c}\text { Number of } \\
\text { Cases of } \\
\text { Gout. }\end{array}$ & $\begin{array}{c}\text { Percentage } \\
\text { of Saturnine } \\
\text { Gout. }\end{array}$ & Remarks. \\
\hline $\begin{array}{ll}\text { Duckworth, D. } & \ldots \\
\text { Garrod, A. } & \ldots \\
\text { Lancereaux } & \ldots \\
\text { Lindsay .. } & \ldots \\
\text { Pye Smith } & \ldots\end{array}$ & $\begin{array}{l}136 \\
(?) \\
24 \\
482 \\
61\end{array}$ & $\begin{array}{r}18 \cdot 0 \\
35 \cdot 0 \\
33 \cdot 0 \\
22 \cdot 8 \\
\\
3 \cdot 5\end{array}$ & $\begin{array}{l}\text { St. Bartholomew's Hospital. } \\
\text { St. Bartholomew's Hospital. } \\
\text { Paris (in saturnine nephritis). } \\
\text { Mineral Water Hospital, } \\
\text { Bath. } \\
\text { Guy's Hospital. }\end{array}$ \\
\hline
\end{tabular}

On the other hand, in Freich's clinic in Berlin, out of 163 cases of lead poisoning there were no cases of gout. In Newcastle, where there are a large number of cases of lead impregnation, gout is not seen in association with that condition. In Glasgow, Edinburgh and Dublin the physicians state that gout in association with lead is unknown.

It is not only manual labourers who suffer from saturnine gout; certain very severe cases of gout among the upper classes have been due to a slightly excessive proportion of lead in the drinking water. Van Breemen quotes a case. A well-to-do Englishman living in one of the eastern counties consulted him on account of severe and frequent attacks of acute gout. The patient was put on a strict régime, but at the end of two months showed no improvement. Van Breemen then went into the question of the water supply, and the sample sent to Utrecht proved to contain a somewhat excessive amount of lead. The fault in the water supply was therefore corrected, and for the next two or three years the patient had no attacks of gout. Some three years after the original consultation the patient 
stayed at a large hotel in the West of England, and this visit was followed by a severe attack of gout. The patient communicated with Dr. Van Breemen, and the water supply of the hotel was tested and found to contain an excessive quantity of lead.

There are many peculiarities about the action of alcohol in producing an attack of gout; for instance, beer will bring on an attack in one man who can take champagne with impunity, while other men can take beer and not champagne. Most gouty subjects get mild twinges after taking port, but reasonable quantities of whisky seldom produce gout. Certain physicians explain the action of alcohol by its action on the liver, but if this were so why should the small quantity of alcohol in port be so much more deadly than a large amount of alcohol in whisky? Would it not be more reasonable to say that the gouty patient is allergic to certain constituents associated with alcoholic beverages, just as the hay-fever patient may be allergic to pollen from Timothy grass and not to that of other forms of grass?

An analogous susceptibility of tissues to different alcoholic beverages was pointed out by Ritchie Russell in connection with a case of myotonia, who had found that his muscles were sufficiently released to enable him to dance through a whole evening if he consumed a pint of a certain kind of ale, but it was impossible to reproduce this effect with any other form of alcohol from " absolute" downwards.

It is a curious fact, so far unexplained, that if we assume that the susceptibility to foodstuffs producing such a specific effect as an acute attack of gout is an hereditable variant, the food substances vary to such an extent.

So far as we have been able to ascertain no investigation has been carried out as to whether gouty subjects deriving from a gouty ancestor are susceptible to the same foodstuffs, but clearly this is a proposition which might well be proved or disproved.

An argument in favour of the allergic nature of the acute attack of gout is its sudden onset and sudden relief.

This points to the reaction being an antigen-antibody reaction. If, as has been suggested, a low-grade infective arthritis or even an actual necrosis of tissue precedes the deposits of biurate crystals, it is difficult to understand the complete remission and rapid relief in cases of gout, for in favourable cases- 
that is to say, those in which the acute attack is not too prolonged or is not repeated too frequently-there may be no obvious residual affection of the joint.

It is only in the stage of acute attacks that the administration of the time-honoured specific colchicum is most useful. Its pharmacological action is up to the present a mystery, since all its proved actions on the body can be brought about more potently by other agencies, but these latter do not have a specific action on gout.

In the consideration of gout it is important to recognise two definite stages: $(a)$ the initial acute onset which so closely resembles an allergic attack, $(b)$ the effect on the joints of repeated attacks. The deposition of crystals of biurate interferes with the smooth action of the joint and introduces an element of trauma, and in the case of a long attack or repeated attacks of gout a condition which started as gout ends by becoming a chronic traumatic arthritis, which latter condition is not benefited appreciably by colchicum and requires quite different treatment, largely by physical measures, which may be strongly contra-indicated in the acute allergic stage. The general symptoms-fever, mental irritability and depression-do not negative the suggestion that the attack is allergic, while the rapid sedimentation rate, the leucocytosis, and the shift of the polynuclear count may all be found in certain phases of allergic conditions. It may be noted, however, that there is no eosinophilia in gout.

It must be admitted, however, that the above phenomena are more common in cases of infection than in cases of allergy, and some observers have suggested that gout has an infective rather than an allergic origin. Llewellyn (1920) definitely puts forward the suggestion that the "latent tissue peculiarities of the gouty through the agency of infections become manifest as gout, and that the said organisms excite the inflammatory reaction with sequential uratic deposition."

But the onset of an acute attack of gout as a direct result of two glasses of port or a large tumbler of cider is a strong argument against the infective theory, as is also the fact that complete remission occurs in spite of the focus of infection being untreated. Again, in many cases freedom from attacks of gout follows a strict dietetic régime, although this strict régime cannot possibly affect the septic tooth, the septic tonsil or infected 
sinus. Everyone admits that the removal of a septic focus may be of great value in the treatment of gout. Many other diseases benefit in a similar manner. This does not prove that the septic focus is the cause of the disease; it may be an additional burden, which when removed enables the body to tackle successfully certain abnormalities.

In view of the importance of vitamins in metabolism, particularly the action of vitamin $B_{1}$ in the oxidation of carbohydrate and perhaps lactic acid, the recent work of Vorhaus and Kramer (1938) is interesting. They record twenty-five cases of gout treated with thiamin chloride (vitamin $\mathrm{B}_{1}$ ). The most striking observation as the result of this administration was the flare-up of the symptoms and signs, but, as they remark, additional observations by other workers are necessary to prove a relationship between gout and vitamin $B_{1}$.

There is no question, as Thomson (1938) has pointed out, that derangement of the liver is traditional in gouty subjects. As we have already stated, the explanation that the liver cannot deal adequately with alcohol lacks proof, and it may be that one factor in gout is the deficiency of some essential substance, hormonic or otherwise, in the liver, or more generally, in the reticulo-endothelial system. It is interesting to note that Barker and Oriel (1928) have shown that just before and during an allergic attack they found a positive Van den Bergh reaction of the biphasic type in a large proportion of cases. They believe that these changes are indications of a disturbance of hepatic function.

This leads us to consider the peculiar phenomena associated with error in purine metabolism, which, as has been said, may be an hereditable variant.

All mammals, with the exception of man, are able to destroy uric acid rapidly. This destruction is caused by uricase, a ferment found in the liver, kidneys and muscles, except in man, and curiously enough in Dalmatian dogs. In birds, ammonia and lactic acid are synthesised in the liver to form uric acid, but this does not occur in mammals. The only condition analogous to gout in mammals is found in swine, who get deposits of guanine in muscles.

Umber (1910) and his pupils have proved that the excretion of uric acid is delayed in a gouty subject. This has been confirmed by Vogt, Walker Hall and several other observers. Osler 
(1912) states that the slow elimination of uric acid is the most important factor in gout.

Folin (1923), on the other hand, has demonstrated that uric acid injected into gouty patients is excreted as rapidly and completely as in normal controls, and there is ample evidence that in the earlier stages, at least, gouty persons can concentrate uric acid in the urine to as high a level as normal individuals. It would seem, therefore, that the kidney is not at fault, but that there is a tendency to store a substance in the tissues which is a perfectly normal product of metabolism. We may detect here a certain analogy to diabetes. Are we therefore to suppose that some hormone is absent or deficient in gouty persons, as insulin is absent or deficient in diabetes, or perhaps that some enzyme like hæmopoietin is absent as in pernicious anæmia? There is as yet no answer to this question, but it is a point which might indicate a future line of research. Help might be obtained by a further study of the condition in which the levels of uric acid in the blood reach a maximum-namely, leucæmia, a disease of the liver-bone marrow relationship which we now describe as the reticulo-endothelial system. Leucæmics do not suffer from gout, but that is evidently because they do not possess the susceptibility to certain foodstuffs nor the tendency to the deposition of urates, which are presumed to be hereditable variants in gout.

All the above facts fail to explain, however, a sudden deposition of uratic crystals which follows two glasses of port wine or a tumblerful of cider, nor do they explain the rapid and complete absorption of these; and it will be instructive to consider the possibility of explaining the rôle of uric acid in gout from an entirely different standpoint-namely, that uric acid is the result of an attack of gout, : and not the cause. This is suggested by Llewellyn (1920) and is the thesis of Matthieu Pierre Weil (1938). It should be noted that in early cases of gout there is no excess of uric acid in the blood, excepting during the attack. Daniel relates two cases where acute attacks of gout occurred when the blood uric acid was at a subnormal level, the victims being at the time on atophan. The continuous excess is only found after long-continued attacks or when attacks are frequent; therefore a low blood uric acid during a remission does not mean that a given attack of acute pain in a joint cannot be gout. 
An interesting point in relation to the acute attack of gout is the frequency of attacks in early spring and late autumn. It is $\frac{0}{\omega}$ difficult to find an explanation of this phenomenon; the only other $\overrightarrow{\vec{F}}$ group of diseases showing this seasonable attack is the infectious group-measles, scarlet fever and diphtheria, and also rheumatic fever (Rowlands, 1938). Two possibilities occur to the mind: firstly, that seasonable foodstuffs such as rhubarb may be a factor; or it may be a sensitivity of the organism to climatic changes-from summer conditions to winter and again from $\overrightarrow{0}$ winter to summer. That climatic conditions do influence the $\overrightarrow{\vec{\omega}}$ organism is obvious, but the exact nature of the influence is not easy to explain.

In a man between the ages of thirty and forty, who suffers $\overrightarrow{.}$ from an acute attack lasting only a few days, the uric acid in the joint is probably absorbed rapidly by the blood, and Dyce Duckworth (1889) relates a case in which at post-mortem no traces of biurate crystals were found in the big toe of a man of forty-three after two acute attacks of gout in that joint. Where the attack occurs in older men, and lasts from ten days to three $\stackrel{\mathbb{\perp}}{\triangle}$ weeks, the amount of uric acid deposited is too great to be ab- $\overrightarrow{0}$ sorbed rapidly, and the resulting damage to the joint produce by the crystals predisposes that joint to another attack of gout It is by encouraging the excretion of uric acid in the interval between the attacks and thus freeing the joints that cinchophen proves useful. It is well recognised that cinchophen fails to relieve an acute attack of gout. Many have seen and described patients who, starting with typical attacks of gout with complete remission, gradually, with the increase of age, or some lowering disease, such as gastric ulcer, develop a chronic arthritic condition closely resembling rheumatoid arthritis. This fact suggests that the patient with a lower vitality is unable to react to the antigen, whatever it is, with the result that the joint condition fails to clear up.

Weil's suggestion with regard to the deposit of crystals is 음 that the allergic reaction produces an acute response in and about the joint, with an intense concentration of leucocytes in the neighbourhood. Just as in the case of leucæmia, therefore, 요 there is an intense production and intense destruction of leuco- ? cytes, with resultant liberation of uric acid. Since, in gout, this is a local rather than a general process, there is a local deposit of uric acid in the form of biurate crystals and at the same time 
an absorption into the blood stream which, owing to the supposedly inherent error in purine metabolism, cannot be dealt with efficiently, and so uric acid gradually accumulates. But we should remember that these conditions of concentration of leucocytes hold in any suppurative condition where the leucocyte exudation and destruction are far more intense than in gout, and even in gouty subjects there is no evidence that biurates are deposited in the neighbourhood of septic foci.

Tophi tend to be deposited in somewhat avascular tissuesnamely, in cartilage, synovial membrane in joints or bursæ, and in the medulla of bones. In certain advanced cases of gout deposits of biurates have been found in the papillæ of the kidneys (sixteen out of eighty $-\mathrm{N}$. Moore).

In advanced kidney disease neither uric acid nor urea is excreted in normal quantities, and a high content of uric acid in the blood occurs in kidney disease without a necessary association with gout. This indicates that renal defect is not a cause of gout.

All textbooks state that chronic nephritis is a common sequence of gout. In our experience this is rare. In Hill's (1938) figures only nine cases out of a total of ninety-three cases of gout had serious renal inefficiency. It is to be remembered that alcohol, excessive meat intake and lead predispose not only to gout, but to arterio-sclerosis, and it is quite likely that in those cases of gout which develop nephritis the nephritis is due, not to the gout, but to the alcohol, etc., which have also been responsible for the gout.

\section{Clinical Features of Gout}

There is a tendency nowadays to restrict the diagnosis of gout to those cases in which there is a clear history of a typical acute attack or in which tophi can be demonstrated.

Furthermore, there is a widely-held belief that gout is found almost exclusively in men. That it is much commoner in men than in women none will deny, and the fact that men are more subject to trauma, especially in the big toe, that they indulge more freely in alcohol, and that some of them are exposed to lead and other metallic poisons may be a partial explanation. In the much-quoted aphorisms of Hippocrates we learn that eunuchs are immune to gout, whilst in females gout is usually 
delayed until after the menopause. If these statements were true we should have to look for an endocrine factor in the causation of gout. However, Galen states that eunuchs in his day readily begat the disorder, and Seneca, writing of the decadent period of the Roman Empire, states that women rivalled men in their bodily disorders. Nevertheless, frank gout is less uncommon in women, especially after the climacteric, than is generally supposed, and the following two cases occurring in women under forty show that it can and does occur in younger women:

E. B. (charwoman, aged thirty-six) suffered from gout for the last five years. The first attack was in the right big toe, and most of the joints have been affected at one time or another. The father suffered from stone in the bladder, but there was no family history of gout; there was, however, a history of large excess of alcohol. When the patient was first examined she was suffering from a severe attack of gout in the knees, feet and left wrist. There was a deposit of urates in the right olecranon bursa and around the terminal joint of the middle finger of the left hand; no tophi were present in the ears. A skiagram of the left hand showed a transparent area about the size of on pea in the distal end of the second phalanx of the middle fingee (Burt, 1908).

D. B. (a trained nurse, aged thirty-two years). Admitted to the Royal Devonshire Hospital, Buxton, in June, 1927. She gave a history of pain and swelling in the small joints of the hands and feet intermittently for nine years. The onset of the first attack was sudden. On examination the right knee was hot and swollen, and both big toes swollen and tender; there was a tophus in the right ear; blood uric acid (Benedict direct) was $7.95 \mathrm{mgm}$. per cent. The urine contained a trace of albumin, and hyaline and granular casts were present.

Apart from this, however, it is possible that gout may sometimes appear in men, and more particularly in women, in a less spectacular form than that generally described, and thus escape diagnosis. No doubt some cases diagnosed as rheumatoid arthritis in women are of a gouty nature, and Mallory (1910) has shown that $47 \cdot 3$ cases of rheumatoid arthritis in women show a prolongation of the period of exogenous uric acid excretion, and two cases showed increased uric acid excretion during subacute attacks of arthritis. This question requires careful revision. At present probably most physicians would say that 
the differential diagnosis of rheumatoid arthritis and gout presents no difficulties, but we are by no means certain of the truth of such an assertion.

In the young, robust man the violence of the reaction in gout is a marked feature; in fact, no other disease shows such a violent reaction, and it is this reaction which leads to the rapid and complete remission. As the reactions grow milder, a not infrequent condition with the increase of age or lack of vitality, gout takes on a chronic form and may simulate rheumatoid arthritis. In so-called rheumatic gout the thickening of synovial membrane, stiffening and swelling of the small joints without the profound trophic changes characteristic of rheumatoid arthritis, so frequent in the female descendants of gouty men, is possibly an attenuated form of true gout, in which the reaction is too mild to neutralise the antigen, with the resulting development of what is really a chronic traumatic arthritis. Of course, it is possible that a joint damaged by gout is predisposed to infection, and no doubt there are joint lesions the proper diagnosis of which would be infective arthritis superimposed upon gout. In common with other articular tissues subject to the continued offensive of noxious influences, these joints may eventually develop degenerative changes and clinically become diagnosable as typical osteo-arthritic joints. We believe that such an outcome of chronic gout is relatively common.

It is interesting to compare this sequence with that met with in asthma. In the earlier stages the attacks of asthma are apt to clear up, leaving no complications behind, but after several years of asthmatic attacks, particularly if these are frequent, organic changes develop, such as bronchial catarrh, fibrotic changes around the tubes and emphysema. Often the condition is complicated by infection of the bronchi, and the same phenomena may occur in a chronic gouty joint.

Again, intermittent hydrarthrosis is by many considered an allergic phenomenon. In this condition, at first there are complete remissions; gradually, however, organic changes occur, and a chronic arthritis is the result.

Similarly, the arthritis following injections of horse serum is undoubtedly allergic. The condition generally clears up in a few days, but not always. Two nurses have recently been admitted to the Royal National Hospital for Rheumatic Diseases at Bath in whom a mild chronic arthritis followed directly 
in one case antidiphtheric serum and in the other antistreptococcic serum. The arthritis had lasted for months before they were admitted to the hospital, and was not completely cured after six weeks' treatment.

It must be admitted, however, that from the clinical point of view the attacks of serum arthritis in no way resemble attacks of acute gout. Pain, when present, is due to stretching of the capsule, and not to acute inflammation, and there is no redness, heat or œdema.

\section{Fibrositis}

It is noteworthy that in almost every case of gout an associated fibrositis may be found. In the nineteenth century the chief authorities on gout all mention it as a cause of fibrositis. For instance, Garrod (1876) states that gout affecting the muscular system appears to be of the same nature as true gouty inflammation. Duckworth (1889) states that muscular rheumatism is really gouty, and says that uric acid deposits have been found in muscles. This must be very rare, for no other observer has described uric acid in muscles, and the absence of synovial fluid and cartilage and the excellent blood supply make such deposit unlikely.

Llewellyn (1920) states that clinically one meets with all forms of fibrositis in association with acute articular gout. In spite of this, the medical profession is slow in acknowledging a true gouty fibrositis. We have seen attacks of fibrositis in gouty subjects every bit as sudden in their onset as acute attacks in the big toe. Stiffness and pain in the shoulder muscles is a common sequence to over-eating and over-drinking, and, indeed, success often attends treatment identical with that which would be employed in a case of frank gout, including the exhibition of colchicum.

We may therefore have to revert to the ideas of our ancestors to some extent and be less diffident in the employment of the adjective "gouty."

In any case, it is clear that this disease is a reproach to medical science, and that we know little more about it-perhaps clinically not so much-than did our ancestors. 


\section{Summary and Conclusions}

1. Although there have been considerable improvements in, and additions to, the biochemical tests available in the diagnosis of gout, the tendency has been for the differential diagnosis of certain aspects of the disease from other forms of arthritis, especially rheumatoid arthritis, to be more rather than less difficult.

2. The evidence in favour of heredity is overwhelming, even if all cases not showing classical symptoms are excluded. It seems probable that there are at least two heritable factors, but these will only manifest themselves if certain environmental influences are present. These factors are:

1. A sensitiveness to certain articles of diet or certain products of metabolism.

2. A tendency to store uric acid in the body and to precipitate biurate crystals in certain tissues.

3. The attack of gout which should be distinguished from the sequelæ of such an attack or attacks is a typical allergic reaction.

4. Lead absorbed into the tissues may act as a precipitant of an attack, but in the absence of other factors does not cause gout.

5. The delay in excretion of uric acid may be due to the absence of some hormone, as in diabetes, or some enzyme, as in pernicious anæmia, and the factor determining this may be inborn or acquired.

6. The deposition of uratic crystals may be a result rather than a cause of the " attack."

7. Gout is found less exclusively in men than is generally supposed, and certain cases of chronic arthritis, and perhaps of fibrositis, not usually classified as gout, ought to be included in this category.

\section{REFERENCES}

Barber, H. W., AND OrIEL, G. H. (1928): Lancet, ii. 1009-1064.

Bauer, E., Fischer, E., ANd Lenz, F.: "Human Heredity." London, 1931 .

Burt, J. B.: Proc. Roy. Soc. Med., Clin. Sect., 1908, p. 223.

Devonshire Hospital First Research Report, 1928, p. 78.

Duckworth, D.: “ Treatise on Gout," p. 68. London, 1889.

Freund, E.: Proc. of the International Congress of Rheumatism and Hydrology, London, 1938, p. 307. 
GARROD, SIR A.: "Gout and Rheumatic Gout." London, 1876.

Hamrlton, D. J.: Scot. Med. and Surg. Journ., 1900, iv. 289-331.

HILL, L. C. : Proc. of the International Congress of Rheumatism and Hydrology, London, 1938, p. 251.

Hurst, Sir A. F.: Guy's Hospital Gaz., 1936, p. 236.

Llewellyn, R. J.: "Gout." London, 1920.

Mallory, W. J.: Bull. Committee Study of Spec. Dis., iii. 2.

OSLer, Sir W.: "Principles and Practice of Medicine," 8th ed., p. 418, 1912.

Rowlands: Brit. Med. Journ., 1938, ii. 15.

Thomson, F. G.: "A Survey of Chronic Rheumatic Diseases," p. 193. London, 1938.

Thomson, J. A.: "Heredity." London, 1908.

Umber aNd RItzlaff: Deutsch. Kingr. $f$. innere Med., Wiesbaden, 1910.

Vorhaus aNd Kramer: Acta Rheumatica, December, 1938, p. 8.

WeIL, M. P.: Proc. of the International Congress of Rheumatism and Hydrology, London, 1938, p. 237.

$\vec{\rho}$ 